\title{
Resistance to Pyraclostrobin and Boscalid in Botrytis cinerea Isolates from Strawberry Fields in the Carolinas
}

Dolores Fernández-Ortuño, Fengping Chen, and Guido Schnabel, School of Agricultural, Forestry, and Life Sciences, Clemson University, Clemson SC 29634

\begin{abstract}
Fernández-Ortuño, D., Chen, F., and Schnabel, G. 2012. Resistance to pyraclostrobin and boscalid in Botrytis cinerea isolates from strawberry fields in the Carolinas. Plant Dis. 96:1198-1203.

Botrytis cinerea, the causal agent of gray mold disease, is one of the most important plant-pathogenic fungi affecting strawberry. During the last decade, control of gray mold disease in the southeastern United States has largely been dependent on captan and the use of at-risk fungicides with single-site modes of action, including a combination of the quinone outside inhibitor (QoI) fungicide pyraclostrobin and succinate dehydrogenase inhibitor (SDHI) fungicide boscalid formulated as Pristine 38WG. Reports about loss of efficacy of Pristine in experimental fields in North Carolina prompted us to collect and examine 216 single-spore isolates from 10 conventional fields and 1 organic field in North Carolina and South Carolina in early summer 2011. Sensitivity to pyraclostrobin or boscalid was determined using a conidial germination assay with previously published discriminatory doses. Pyraclostrobin- and pyraclostrobin+boscalid-resistant isolates were found in all conventional fields (with some populations revealing no sensitive isolates) and in the organic field. Among the isolates collected, $66.7 \%$ were resistant to pyraclostrobin and $61.5 \%$ were resistant to both pyraclostrobin and boscalid. No isolates were identified

that were resistant to boscalid but sensitive to pyraclostrobin, indicating that dual resistance may have derived from a QoI-resistant population. The molecular basis of QoI and SDHI fungicide resistance was determined in a subset of isolates. Polymerase chain reaction-restriction fragment length polymorphism analysis of the partial cytochrome $b(C Y T B)$ gene showed that pyraclostrobin-resistant isolates possessed the G143A mutation known to confer high levels of QoI fungicide resistance in fungi. Boscalid-resistant isolates revealed point mutations at codon 272 leading to the substitution of histidine to arginine (H272R) or tyrosine (H272Y), affecting the third Fe-S cluster region of the iron-sulfur protein $(\mathrm{SdhB})$ target of SDHIs. The results of the study show that resistance to QoI fungicides and dual resistance to QoI and SDHI fungicides is common in $B$. cinerea from strawberry fields in the Carolinas. Resistant strains were more frequent in locations heavily sprayed with QoI and SDHI fungicides. However, resistance to both fungicides was also found in the unsprayed, organic field, indicating that some resistant strains may have been introduced from the nursery.
\end{abstract}

Strawberry is an important commercial fruit crop, widely grown in all temperate regions of the world; however, those climatic conditions are also suitable for the development of many diseases. In the United States alone, 22,040 ha were cultivated in 2008 and 2,531.7 million pounds of fruit produced (United States Department of Agriculture, National Agricultural Statistics Service, noncitrus fruits and nuts summary). Bacteria (angular leaf spot or bacterial wilt), nematodes (bulb and stem, root-knot, spring dwarf, and so on), and fungi (anthracnose, gray mold) pose threats to strawberry crops. Among fungal diseases, Botrytis cinerea Pers. is one of the most economically important preharvest and postharvest pathogens. It is responsible for gray mold disease and crown rot of strawberry and, due to its ubiquity, affects more than 230 additional plant species worldwide (22). Substantial economic losses resulting from gray mold disease occur not only during the crop-growing season but also after harvest, during storage and transit.

Several fungicides are currently available for gray mold control. Chemical control, however, has been hindered by the emergence of resistant isolates. B. cinerea represents a classical high-risk pathogen in view of fungicide resistance development, due to its high genetic variability, its abundant sporulation and polycyclic nature, and the high number of sprays required for its successful control (26). Over the last 20 years, resistance of $B$. cinerea to anilinopyrimidine, benzimidazole, dicarboximide, hydroxyanilide, and phe-

Corresponding author: G. Schnabel, E-mail: schnabe@clemson.edu

Accepted for publication 5 March 2012.

http://dx.doi.org/10.1094/PDIS-12-11-1049-RE

(C) 2012 The American Phytopathological Society nylpyrrole has been reported in different countries soon after their introduction for the control of gray mold disease $(7,16,47)$.

The quinone outside inhibitors (QoIs), such as pyraclostrobin, are suppressants of $B$. cinerea and commonly used together with succinate dehydrogenase inhibitors (SDHIs) for gray mold control. They display a single-site mode of action that was elucidated in 1981 and that results in a high intrinsic risk of development of resistance to this group of fungicides (8). The fungicidal activity of QoI fungicides relies on their ability to inhibit mitochondrial respiration by binding at the Qo site. This inhibition blocks the transfer of electrons between cytochrome $b$ and cytochrome $c_{l}$, leading to an energy deficiency in the fungal cells by halting the production of ATP and, ultimately, leading to fungal death (13). This fungicide group is considered to be high risk for resistance development (Fungicide Resistance Action Committee [FRAC], QoI fungicides working group).

Several molecular mechanisms associated with QoI sensitivity were reported $(12,15,21,28,43)$, the primary one being target site based, involving mutations in the mitochondrial cytochrome $b$ $(C Y T B)$ gene and resulting in peptide sequence changes that prevent fungicide binding. Three amino acid substitutions-from glycine to alanine at position 143 (G143A), phenylalanine to leucine at position 129 (F129L), and glycine to arginine at position 137 (G137R) - have been detected in the CYTB protein of several phytopathogenic fungi and oomycetes that are resistant to QoIs $(13,14,36)$. Isolates expressing F129L or G137R mutant proteins exhibit moderate (partial) resistance, whereas isolates with G143A exhibit high (complete) levels of resistance that are always associated with the failure of QoIs to control disease.

Boscalid is an SDHI registered for gray mold control. SDHIs prevent mitochondrial respiration by inhibiting the activity of mitochondrial respiratory complex II that comprises a flavoprotein $(\mathrm{Sdh} A)$, an iron-sulfur protein $(\mathrm{SdhB})$ with three iron-sulfur clus- 
ters (S1, S2, and S3), and two membrane-anchored proteins (SdhC and $\mathrm{SdhD}$ ) (17). The SdhA and SdhB subunits form the soluble part of the complex, which has succinate dehydrogenase activity, whereas the SdhC and SdhD subunits are responsible for the quinone reductase activity $(32,44)$. The enzyme plays a crucial role in the tricarboxylic cycle and the mitochondrial transport chain, and its inhibition leads to a block of the cell energy cycle (19).

The site-specific mode of action allows the fungus to develop resistance based on very few genetic modifications. In general, mutations affecting the second and the third iron-sulfur complex (S2 and S3) of SdhB have been reported in laboratory mutants and field isolates of $B$. cinerea (amino acid positions 225, 230, and 272) conferring different levels of resistance to these fungicides $(11,27,38)$. Mutations that resulted in proline to leucine, phenylalanine, or threonine replacements at position 225 (P225L, P225F or $\mathrm{P} 225 \mathrm{~T})$ have been observed in boscalid-resistant laboratory mutants $(11,38)$. Resistant field isolates of $B$. cinerea isolates exhibited the $\mathrm{P} 225 \mathrm{~F}$ and $\mathrm{P} 225 \mathrm{~L}$ modifications (38). Other modifications affecting the second iron-sulfur complex (S2) of $\mathrm{SdhB}$ seem to be Botrytis spp.-specific, such as the one at codon 230 replacing asparagine to isoleucine (N230I; 27). In regard to the third iron sulfur cluster (S3), three possible modifications (H272Y, H272R, and $\mathrm{H} 272 \mathrm{~L}$ ) induced different phenotypes in field isolates of $B$. cinere $a$ and in other phytopathogenic fungi $(2,20,24,27)$. No mutations in the SdhC subunit have been associated with SDHI resistance in $B$. cinerea; however, in the $\mathrm{SdhD}$ subunit, the replacement from histidine to arginine at position 132 (H132R) was found in field-resistant $B$. cinerea isolates (27).

In the southeastern United States, QoI and SDHI fungicides have been frequently used in tank mixture to control gray mold of strawberry, and evidence started to emerge that resistance is developing in experimental strawberry fields in North Carolina (34). Additionally, QoI fungicides were used starting in 1998 to control anthracnose disease of strawberry. In the current study, strawberry fruit with gray mold symptoms from commercial fields in North Carolina and South Carolina were collected during the spring and summer of 2011. The pathogens were isolated and characterized for pyraclostrobin and boscalid sensitivity and for molecular alterations of the target genes. Specific objectives were to assess the occurrence of $B$. cinerea strains resistant to pyraclostrobin and boscalid in the Carolinas and to determine the molecular basis of resistance.

\section{Materials and Methods}

Fungal isolates and culture conditions. In total, $216 \mathrm{~B}$. cinerea isolates were obtained from strawberry fruit with symptoms indicating gray mold disease between April and June 2011. The samples were collected from commercial fields encoded HP, MV, NC, and SBY of North Carolina and FLOR, GIK, JEY, KUD, MER, MOD, and WIC of South Carolina (Table 1). For single-spore isolation, conidia were scraped off without touching the fruit using a sterile scalpel and suspended in $1 \mathrm{ml}$ of water containing $1 \%$ (vol/vol) Tween-20 (Promega Corporation, Madison, WI). Then, $200 \mu \mathrm{l}$ of the suspension was spread on $1.5 \%$ (wt/vol) water-agar plates (Acros Organics, NJ) amended with $0.1 \%$ (vol/vol) lactic acid (Sigma-Aldrich Chemie GmbH, Steinheim, Germany). After incubation at $22^{\circ} \mathrm{C}$ for 24 to $36 \mathrm{~h}$, one germinated conidium was transferred onto potato dextrose agar medium (PDA; Difco Laboratories, Sparks, MD) plates and incubated $48 \mathrm{~h}$ at $22^{\circ} \mathrm{C}$. For long-term storage, mycelium of each isolate was maintained at $-80^{\circ} \mathrm{C}$ in $80 \%$ (vol/vol) glycerol (Fisher Scientific, NJ).

All isolates were grown on oatmeal agar $(60 \mathrm{~g}$ of oatmeal, $12 \mathrm{~g}$ of agar, $50 \mathrm{~g}$ of sucrose, $10 \mathrm{~g}$ of sodium nitrate, and $1,000 \mathrm{ml}$ of distilled water) in 9-cm-diameter polystyrene petri dishes for 8 days at $22^{\circ} \mathrm{C}$, and conidia were harvested by flooding the dish surface with $2 \mathrm{ml}$ of sterile distilled water and pipetting the suspension gently off the dish surface. Spore suspensions were filtered through a $34-\mu \mathrm{m}$ nylon mesh to remove fungal mycelium, adjusted to $4 \times 10^{5}$ spores $/ \mathrm{ml}$, and stored at $4^{\circ} \mathrm{C}$ for up to $48 \mathrm{~h}$ prior to use (42).

Sensitivity of $B$. cinerea isolates to pyraclostrobin and boscalid. Pyraclostrobin (Cabrio EG fungicide [20\% wt/wt]; BASF Corporation, Research Triangle Park, NC) and boscalid (Endura fungicide $[70 \% \mathrm{wt} / \mathrm{wt}]$; BASF Corporation) were used for in vitro assays based on conidial germination at discriminatory doses, as previously described (42). The assay distinguishes pyraclostrobinresistant isolates from sensitive isolates at $10 \mathrm{mg} /$ liter (only germ tubes of resistant isolates develop). Boscalid-resistant isolates (germ tube growth clearly visible at $50 \mathrm{mg} / \mathrm{liter}$ ) are distinguished from sensitive isolates (no growth at $50 \mathrm{mg} /$ liter but growth at $1 \mathrm{mg} /$ liter) and highly sensitive isolates (no germ tube growth at $1 \mathrm{mg} / \mathrm{liter}$ ).

For each isolate and each fungicide concentration, a 40- $\mu$ d drop of spore suspension was streaked across the length of the corresponding medium to ensure a good spread of conidia. For the QoI fungicide pyraclostrobin, autoclaved and cooled malt extract agar (1\% [wt/vol]; EMD Chemicals Inc., Darmstadt, Germany) was amended with pyraclostrobin at $10 \mathrm{mg} /$ liter and the alternative oxidase inhibitor salicylhydroxamic acid at $100 \mathrm{mg} / \mathrm{liter}$ (31). For the SDHI boscalid, $0.5 \%$ (wt/vol) yeast extract agar (EMD Chemicals Inc.) was used in order to avoid the interference of sugars with the assay (39). The medium was augmented with boscalid at 1 and $50 \mathrm{mg} / \mathrm{liter}$. Experiments were replicated three times. Germination was assessed visually under the microscope (OLYMPUS BX41TF; Olympus Optical Co. Ltd., Japan).

DNA extraction and polymerase chain reaction amplification. Isolates of B. cinerea were cultured on PDA plates at $22^{\circ} \mathrm{C}$, and aerial mycelia as well as conidia formed on a colony were collected using a stainless spatula. Genomic DNA was extracted and purified according to Chi et al. (10). The partial CYTB gene was polymerase chain reaction (PCR) amplified with primers Qo13ext (5'-GGTATAACCCGACGGGGTTATAGAATAG-3') and Qo14ext (5'-AACCATCTCCATCCACCATACCTACAAA-3'). The iron-sulfur protein $(S d h B)$ target gene of SDHI fungicides was amplified using primer pair IpBcBeg (5'-CCACTCCTCCA

Table 1. Origin, number, and code of isolates and history of fungicide exposure of Botrytis cinerea from commercial strawberry fields collected in 2011

\begin{tabular}{|c|c|c|c|c|}
\hline \multirow[b]{2}{*}{ State } & \multirow[b]{2}{*}{ Number of isolates } & \multirow[b]{2}{*}{ Isolate code } & \multicolumn{2}{|c|}{ Number of sprays per season ${ }^{a}$} \\
\hline & & & Pyraclostrobin & Boscalid \\
\hline North Carolina & 37 & SBY & $>3$ & $>3$ \\
\hline North Carolina & 11 & $\mathrm{NC}$ & 2 & 2 \\
\hline North Carolina & 33 & HP & $\mathrm{n} / \mathrm{a}$ & $\mathrm{n} / \mathrm{a}$ \\
\hline North Carolina & 11 & MV & 2 & 2 \\
\hline South Carolina & 21 & GIK & 2 & 2 \\
\hline South Carolina & 25 & JEY & $>5$ & $>5$ \\
\hline South Carolina & 21 & KUD & 5 & 5 \\
\hline South Carolina & 13 & FLOR & $\mathrm{n} / \mathrm{a}$ & $\mathrm{n} / \mathrm{a}$ \\
\hline South Carolina & 3 & MER & 2 & 2 \\
\hline South Carolina & 21 & WIC & 0 & 0 \\
\hline South Carolina & 20 & MOD & $>3$ & $>3$ \\
\hline
\end{tabular}

\footnotetext{
${ }^{a}$ Number of sprays applied per season between 2009 and 2011 based on grower testimony. All growers reported to have used pyraclostrobin+boscalid in
} form of Pristine (BASF) formulated product; $\mathrm{n} / \mathrm{a}=$ not available. 
TAATGGCTGCTCTCCGC-3') and IpBcEnd2 (5'-CTCATCAA GCCCCCTCATTGATATC-3'). All primers and PCR conditions were previously reported (27). PCR reactions were carried out in an iCycler Thermal Cycler (Bio-Rad Laboratories Inc., Hercules, CA) in a final volume of $50 \mu$ l containing 2.5 units of Takara LA Taq polymerase (Takara Bio Inc., Japan), $5 \mu$ of $10 \times$ LA PCR buffer II, $2.5 \mathrm{mM}$ each dNTP, 10 pmol of each primer, and $50 \mathrm{ng}$ of fungal template DNA. PCR products were separated in ethidiumbromide-stained 1\% (wt/vol) agarose gels (Thermo Scientific, Rockford, IL), run in $1 \times$ Tris-Borate-EDTA buffer, and exposed to UV light to visualize DNA fragments. $S d h B$ gene PCR products were purified using the ExoSAP-IT PCR purification kit (USB Corporation, Cleveland) following the manufacturer's instructions and sequenced in both directions at the Clemson University Genomics Institute, Clemson, SC using LiCor dye-terminator sequencing technology.
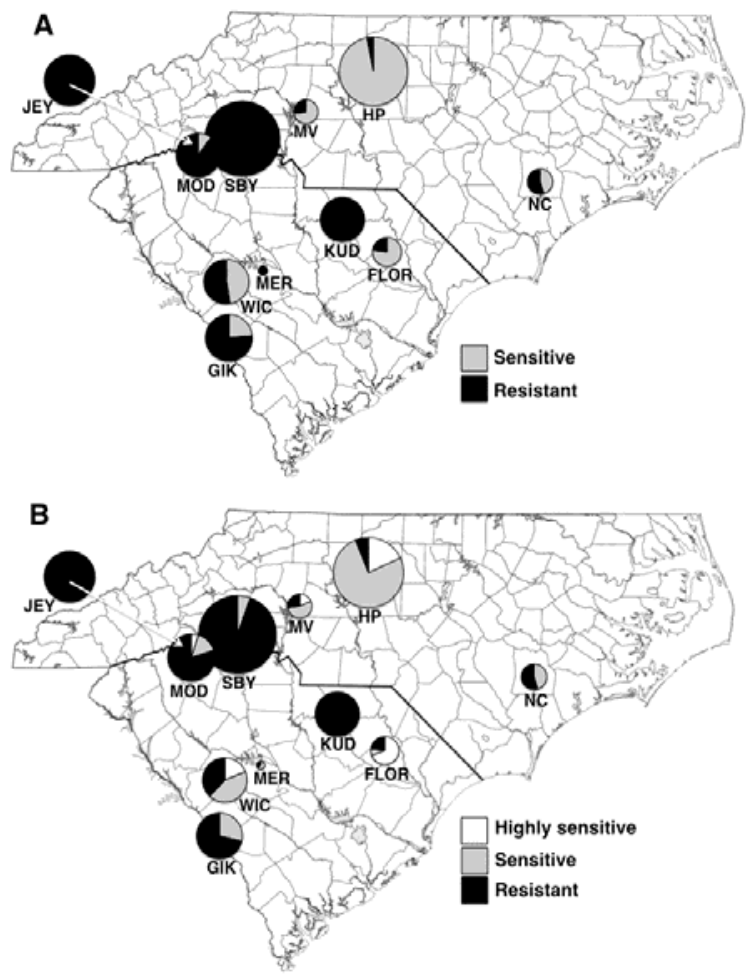

Fig. 1. Frequency of Botrytis cinerea isolates highly sensitive, sensitive, and resistant to $\mathbf{A}$, pyraclostrobin and $\mathbf{B}$, boscalid is indicated in circles as white, gray, and black, respectively. The circle diameter corresponds to the number of isolates tested in each location. The white arrow indicates the location of the center of the JEY circle.
Restriction fragment length polymorphism analysis. QoI-resistant isolates of phytopathogenic fungi often possess a single point mutation at amino acid codon 143 of the fungicide-targeted CYTB protein (13). In many cases, one nucleotide base change from guanine to cytosine occurs at amino acid codon 143, resulting in the substitution of glycine with alanine. To investigate a potential nucleotide alteration at amino acid position 143 in $B$. cinerea isolates sensitive and resistant to pyraclostrobin, $4 \mu \mathrm{l}$ of an unpurified $C Y T B$ PCR fragment obtained with primers Qo13ext and Qo14ext was digested with restriction enzyme Fnu4HI (New England Biolabs, Beverly, MA) at $37^{\circ} \mathrm{C}$ for $2 \mathrm{~h}$, according to the manufacturer's recommendations. Digested fragments were visualized by electrophoresis in $2 \%$ agarose gels.

\section{Results}

Sensitivity of $B$. cinerea isolates to pyraclostrobin and boscalid. Among the 216 field isolates collected from various locations in the Carolinas, 144 isolates $(66.7 \%)$ were resistant to pyraclostrobin. Resistance was found in every location, not always in combination with sensitive isolates (Fig. 1A). In three locations (JEY, KUD, and SBY) all isolates were found to be resistant. In total, 133 isolates $(61.6 \%)$ were resistant to both pyraclostrobin and boscalid, $61(28.2 \%)$ were sensitive to boscalid, and 22 $(10.2 \%)$ were highly sensitive to boscalid. Pyraclostrobin+ boscalid-resistant and -sensitive isolates were present in all but two locations; locations JEY and KUD revealed only pyraclostrobin+boscalid-resistant isolates (Table 2; Fig. 1B). Only 72 isolates of the total population were sensitive to both fungicides and 11 isolates were resistant to pyraclostrobin and sensitive to boscalid (Table 2). No isolates were identified that were resistant to boscalid but sensitive to pyraclostrobin.

Detection of G143A mutation. In this study we used the PCRrestriction fragment length polymorphism (RFLP) method described by Leroux et al. (27) for rapid detection of the G143A mutation in our $B$. cinerea population. First, a 560-bp CYTB fragment was amplified with primers Qo13ext and Qo14ext; then, the fragment was digested with Fnu4HI, which recognizes the $5^{\prime}$ GCNGC- $3^{\prime}$ nucleotide pattern. In the presence of the mutation, the digestion revealed a two-band profile with fragments of 318 and $242 \mathrm{bp}$ in length (Fig. 2A); the fragment of $560 \mathrm{bp}$ remained undigested in the absence of the mutation (Fig. 2A). The fragments amplified from the 14 pyraclostrobin-sensitive isolates remained undigested, while the fragments from the 48 pyraclostrobin-resistant isolates revealed the above-mentioned restriction patters. Therefore, the G143A substitution was present in all pyraclostrobin-resistant but in none of the sensitive isolates (Table 2; Fig. 2B). No intron was observed in any of the $C Y T B$ fragments amplified.

Molecular analysis of the SdhB subunit. DNA extracted from a total of 59 isolates ( 28 boscalid-resistant and 31 boscalid-sensitive) was used as templates in PCR amplifications. The fragment amplified with primers IpBcBeg and IpBcEnd2 was approximately

Table 2. Sensitivity phenotype and presence or absence of associated point mutations in the cytochrome $b(C Y T B)$ and succinate dehydrogenase iron-sulfur protein $(S d h B)$ genes of Botrytis cinerea isolates

\begin{tabular}{|c|c|c|c|c|c|}
\hline Isolates & $\begin{array}{l}\text { Number of } \\
\text { isolates }\end{array}$ & $\begin{array}{l}\text { Pyraclostrobin } \\
\text { sensitivity }^{\mathbf{a}}\end{array}$ & $\begin{array}{l}\text { G143A mutation } \\
\text { in } C Y T B^{\mathrm{b}}\end{array}$ & $\begin{array}{c}\text { Boscalid } \\
\text { sensitivity }\end{array}$ & $S d h B$ alteration ${ }^{c}$ \\
\hline $\begin{array}{l}\text { Flor1-Flor3, Flor5, Flor9-13, Hp13, Hp19-20, Hp22, Hp32, } \\
\text { Hp34, Mv8, Mv10, Wic2, Wic5, Wic16 }\end{array}$ & 20 & $\mathrm{~S}$ & Absent ( 5 of 5$)$ & SS & None (11 of 11) \\
\hline $\begin{array}{l}\text { Flor4, Gik1-2, Gik4, Gik6-7, Hp1-12, Hp14-15, Hp17-18, } \\
\text { Hp21, Hp23-31, Mv1-2, Mv5-7, Mv9, Mod9-10, Nc1, Nc3-4, } \\
\text { Nc8, Nc10, Wic6, Wic8-9, Wic13, Wic19-21 }\end{array}$ & 52 & $\mathrm{~S}$ & Absent (9 of 9) & $\mathrm{S}$ & None (13 of 13) \\
\hline Mod4, Wic14 & 2 & $\mathrm{R}$ & Present $(2$ of 2$)$ & SS & None $(1$ of 1$)$ \\
\hline Gik5, Gik8, Mer2, Mer3, Mod5, Sby7, Sby15, Wic1, Wic11 & 9 & $\mathrm{R}$ & Present ( 5 of 5$)$ & $\mathrm{S}$ & None $(6$ of 6$)$ \\
\hline $\begin{array}{l}\text { Flor6-8, Gik3, Gik9-21, Hp16, Jey1-25, Kud1-21, Mer1, Mod1- } \\
\text { 3, Mod6-8, Mod11-20, Mv3-4, Mv11, Nc2, Nc5-7, Nc9, } \\
\text { Nc11, Sby1-6, Sby8-14, Sby16-37, Wic3-4, Wic7, Wic10, } \\
\text { Wic12, Wic15, Wic17-18 }\end{array}$ & 133 & $\mathrm{R}$ & Present (41 of 41) & $\mathrm{R}$ & $\begin{array}{l}\mathrm{H} 272 \mathrm{R} \text { and } \mathrm{H} 272 \mathrm{Y} \\
(23 \text { and } 5, \\
\text { respectively, of } \\
28)\end{array}$ \\
\hline
\end{tabular}

${ }^{a}$ SS, highly sensitive; S, sensitive; R, resistant. Pyraclostrobin at $10 \mathrm{mg} /$ liter; boscalid was tested at $1 \mathrm{and} 50 \mathrm{mg} / \mathrm{liter}$.

b The G143A mutation was detected using Fnu4HI restriction digestion of the CYTB fragment amplified with primers Qo13ext and Qo14ext.

c The $S d h B$ gene was amplified with primers IpBcBeg and IpBcEnd2. Last number in parentheses indicates total number of isolates tested. 
$950 \mathrm{bp}$ in length for all isolates. Sequencing analysis revealed nucleotide variations that corresponded with amino acid changes at position 272, affecting the third Fe-S cluster region (Fig. 3). In all, 5 of 28 boscalid-resistant isolates (GIK17, GIK20, KUD14, MOD20, and MV11) had the replacement of the histidine residue by a tyrosine residue at position $272(\mathrm{H} 272 \mathrm{Y})$. Replacement of histidine by arginine ( $\mathrm{H} 272 \mathrm{R})$ was observed in the remaining isolates (FLOR6, GIK3, GIK10, GIK11, GIK12, HP16, JEY10, KUD3, KUD8, MER1, MOD7, MOD11, MOD13, MOD15, MV4, SBY11, SBY19, SBY24, SBY25, SBY35, WIC7, WIC10, and WIC17). The SdhB subunit of all boscalid-sensitive isolates revealed the wild-type sequence (Table 2). No other amino acid substitutions were detected.

\section{Discussion}

The development of resistance to QoIs and SDHIs in the gray mold pathogen $B$. cinerea is a serious concern for commercial strawberry growers. Our study shows that this concern is justified and that resistance has emerged in the Carolinas. In fact, our study shows that resistance to pyraclostrobin and boscalid is widespread. Resistance was present even in location WIC that had not been sprayed with QoI or SDHI fungicides for the last 3 years. Migration of resistant strains into this field was unlikely because there were no other strawberry fields within $8 \mathrm{~km}$ of the WIC location and the field was surrounded by crops (peach, plum, and Muscadine grape) that are not generally susceptible to gray mold disease. Although unlikely due to the scarcity of commercial strawberry fields in this part of South Carolina, it is theoretically possible that fruit pickers inoculated the WIC field with spores from conventional fields. The most likely scenario is that resistant isolates were introduced with the transplants from an undisclosed nursery. Nurseries routinely use fungicides to keep strawberry planting material such as plugs and bare root plants disease free but it is unknown if the nursery supplier used QoI or SDHI fungicides for

\section{A}

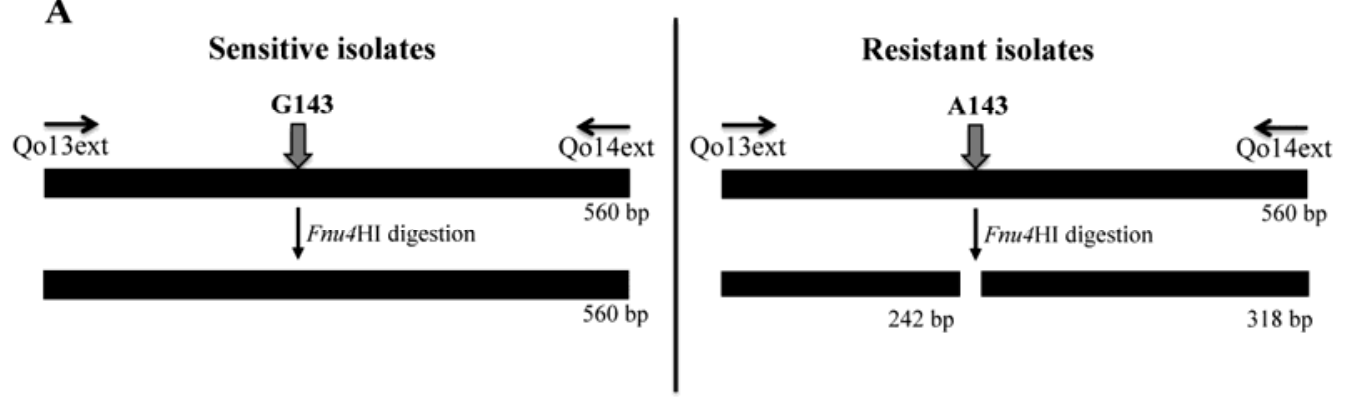

B

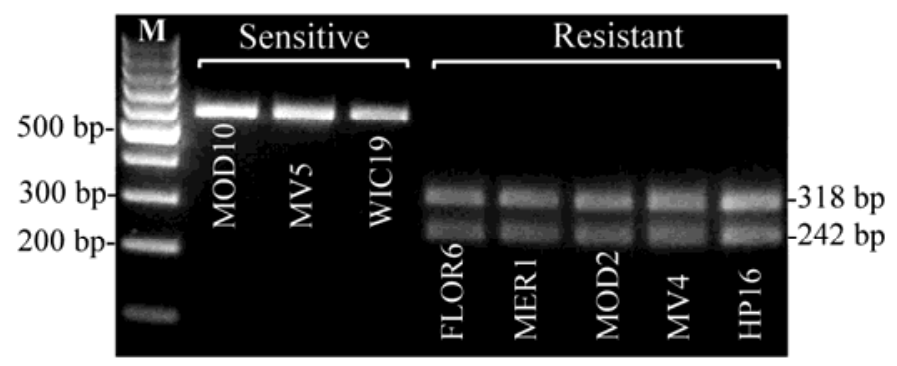

Fig. 2. Restriction fragment length polymorphism analysis of cytochrome $b$ (CYTB) alleles from Botrytis cinerea isolates sensitive and resistant to pyraclostrobin. A, The Fnu4HI restriction enzyme was unable to cut the 560-bp amplification products at the wild-type G143 position but did cut the mutant at the A143 position. B, The presence or absence of this mutation was detected by digesting the CYTB amplification products with the restriction enzyme Fnu4HI, followed by electrophoresis on $2 \%$ agarose gels. Isolate names are shown below the respective lanes. $M=$ GeneRuler 100-bp DNA ladder market (Fermentas Inc., Glen Burnie, MD).

$$
\begin{aligned}
& \text { Boscalid-Phenotype codon } \\
& \text { Sensitive } \begin{cases}\text { AY726619 } & \text { GGATAACAGCATGAGTTTGTACAGATGTCACACTATTCTCAACTGCTCGAGGACATGTCC } \\
\text { FLOR2 } & \text { GGATAACAGCATGAGTTTGTACAGATGTCACACTATTCTCAACTGCTCGAGGACATGTCC } \\
\text { HP30 } & \text { GGATAACAGCATGAGTTTGTACAGATGTCACACTATTCTCAACTGCTCGAGGACATGTCC }\end{cases} \\
& \mathrm{H} 272 \mathrm{Y}
\end{aligned}
$$

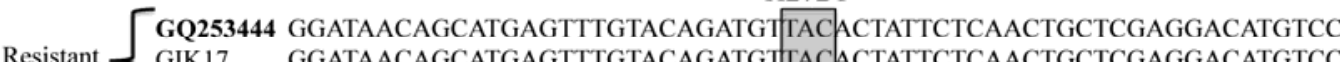

$$
\begin{aligned}
& \text { MOD20 GGATAACAGCATGAGTTTGTACAGATGT[ACACTATTCTCAACTGCTCGAGGACATGTCC } \\
& \text { Resistant } \begin{cases}\text { HQ253445 } & \text { GGATAACAGCATGAGTTTGTACAGATGTCGCACTATTCTCAACTGCTCGAGGACATGTCC } \\
\text { FLOR6 } & \text { GGATAACAGCATGAGTTTGTACAGATGTCGCACTATTCTCAACTGCTCGAGGACATGTCC } \\
\text { HP16 } & \text { GGATAACAGCATGAGTTTGTACAGATGTCGChCTATTCTCAACTGCTCGAGGACATGTCC } \\
\text { JEY10 } & \text { GGATAACAGCATGAGTTTGTACAGATGTCGCACTATTCTCAACTGCTCGAGGACATGTCC }\end{cases} \\
& \text { H272L }
\end{aligned}
$$

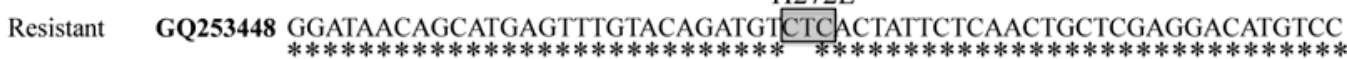

Fig. 3. Partial nucleotide sequences of the succinate dehydrogenase iron-sulfur protein B (SdhB) gene in boscalid-sensitive and -resistant field isolates of Botrytis cinerea. Nucleotides encoding amino acid 272 are boxed. Codons in gray indicate mutations that cause amino acid substitutions in sequences from our isolates or from GenBank (AY726619, GQ253444, GQ253445, and GQ253448). 
disease control. As of 2012, the labels for Abound and Pristine did not specifically prohibit their use in nurseries. Our data suggest that resistance management should start at the nursery level. The conventional locations JEY, KUD, MOD, and SBY were characterized by a very high frequency of resistant isolates. These locations were also sprayed three times or more per season since at least 2008 with Pristine fungicide. This suggests that selection for pyraclostrobin+boscalid resistance may have occurred during the growing season in these locations.

We observed a high frequency $(61.5 \%)$ of dual resistance in almost every location we sampled, which challenges current recommendations for gray mold control. Southeastern strawberry growers and, presumably, nurseries have been using the pyraclostrobin+boscalid combination formulated as Pristine; thus, both chemical classes were applied together frequently since 2002. QoI fungicide azoxystrobin was registered even before that, in 1998, in form of Abound 2.08 flowable fungicide for control of strawberry anthracnose. The results suggest that the use of Pristine in nurseries and conventional fields exercised selection pressure for the development of resistance to both fungicides. Dual resistance to QoIs and SDHIs has previously been reported for $B$. cinerea in laboratory-induced QoI-resistant strains (29) and field isolates from apple (25), berries (27), and kiwifruit (6) but not at frequencies as high as in this study. The high frequency of dual resistance observed in this study and the association with the frequent and almost exclusive use of the combined QoI and SDHI product in Pristine also raises doubt about the validity of the company-driven tank mixture approach for resistance management.

The fact that we only found isolates resistant to pyraclostrobin or pyraclostrobin+boscalid but not to boscalid alone, combined with the fact that azoxystrobin was used since 1998 for anthracnose control of strawberry, suggests that QoI fungicide resistance may have emerged prior to the emergence of dual resistance. The later use of the pyraclostrobin-boscalid mixture for gray mold control may have continued selection for QoI resistance while also selecting for strains with dual resistance. Whether dual resistance actually derived from QoI-resistant strains is unknown but more plausible than the emergence of strains with dual resistance from a completely sensitive population. Therefore, the application of tank mixtures of two site-specific fungicides to populations with existing resistance to one of the two (or more) ingredients may not be a good resistance management practice, assuming that dual resistance derives from single resistance (as suggested in this study). This hypothesis was also discussed in an effort to explain respiration inhibitor resistance development in Alternaria alternata from pistachio (1), B. cinerea from kiwifruit (6), Didymella bryoniae from watermelon $(40,41)$, and other phytopathogenic fungi (2). If boscalid had been available as a solo fungicide, it could have been used in alternation or mixture with chemical classes other than QoIs for resistance management and resistance may have been delayed. QoIs and SDHIs are now virtually useless for gray mold control in the Carolinas until a sensitive population will replace a very large portion of the currently existing resistant population.

QoI resistance in our samples was associated with the amino acid substitution of glycine for alanine at codon 143 (G143A). This alteration has already been identified in 27 fungi listed at the FRAC website (http://www.frac.info/frac/index.htm). The mutation causes a high degree of resistance and, consequently, loss of disease control. High levels of QoI fungicide resistance in $B$. cinerea from other crops such as cucumber, eggplant, kiwifruit, and tomato were associated with the same amino acid substitution $(5,6,23,27,46)$. Some studies observed heteroplasmy of $C Y T B$ (i.e., the coexistence of wild-type and mutant alleles in the same isolate). The wild-type sequence often was present in the majority of resistant isolates, indicating that the proportion of mutated $C Y T B$ alleles was very low (21). Heterogeneity of the $C Y T B$ gene was not observed in the isolates we studied. The amino acid alterations found in this study confer qualitative resistance to QoIs and SDHIs; thus, an increase in field rate will not improve their efficacy.
Resistance to the SDHI boscalid was based on a single amino acid change in the SdhB subunit. In many fungi, the highly conserved histidine residue (equivalent to $\mathrm{H} 272$ in $B$. cinerea) in the $\mathrm{SdhB}$ subunit is responsible for SDHIs resistance $(9,18)$. The role of this codon in resistance was described in laboratory-induced carboxin (SDHI)-resistant isolates in Aspergillus oryzae (H249Y/L/N), Mycosphaerella graminicola (H267Y/L), Pleurotus ostreatus (H239L), and Ustilago maydis (H252L) $(9,18,24,35,37)$. More recently, field isolates resistant to boscalid and carrying a mutation at this codon have also been observed in populations of Corynespora cassiicola on cucurbits in Japan (H278Y) (30); or the substitution H277Y/R in Alternaria alternata from pistachio (3) and in $D$. bryoniae, the causal agent of gummy stem blight of watermelon (4). In our study, the comparison of $S d h B$ sequences between boscalid-sensitive and -resistant isolates also showed alterations of the $\mathrm{H} 272$ codon but different alleles were found at that position. The 28 boscalid-resistant isolates analyzed on a molecular level revealed the amino acid substitution from histidine to arginine (H272R) or to tyrosine (H272Y). H272R was most common in our samples. This finding is consistent with a previously published report, where the mutations $\mathrm{H} 272 \mathrm{R} / \mathrm{Y}$ were found in boscalid-resistant field isolates of $B$. cinerea from apple, H272R being the most frequent genotype (45). However, Leroux et al. (27) described three possible alleles (H272Y, H272R, and H272L) in $B$. cinerea isolates that seemed to induce different phenotypes. The H272Y genotype was the most frequent in French and German vineyards. The dominance of a mutation type in the $B$. cinerea $\mathrm{SdhB}$ subunit could be associated with a particular geographic region and crop species.

Despite the high frequency of QoI- and SDHI-resistant isolates in strawberry fields that were sprayed with Pristine, producers did not experience control failure in the 2011 season. In fact, in many locations, we struggled to collect a sufficient number of isolates for scientific studies. This apparent discrepancy may be explained by several things. First, all growers started the season with very little inoculum. That is because strawberry fields were grown on plasticulture where fumigated fields can be expected to be virtually free from last season's plant debris that could have harbored inoculum. Also, asymptomatic plug plants were obtained from nurseries carrying, presumably, very little inoculum in the form of latent infections. Second, the spring of 2011 was very dry, providing nonfavorable conditions for a disease epidemic. In fact a disease support system (33), which was used to collect and analyze weather data at two locations in South Carolina, indicated only four infection periods for $B$. cinerea during the entire strawberry crop season in South Carolina (data not shown). Third, the majority of producers alternated Pristine with other, unrelated chemical classes such as captan and fenhexamid for gray mold control.

Regardless of the origin of resistance in $B$. cinerea affecting strawberry fields in the Carolinas, producers must be careful with the use of QoI and SDHI fungicides for gray mold control in coming seasons. The widespread occurrence and high frequencies of resistance justifies the implementation of currently nonexistent resistance-monitoring programs in this region.

\section{Acknowledgments}

Technical contribution number 6042 of the Clemson University Experiment Station. This material is based upon work supported by the United States Department of Agriculture (USDA) Cooperative State Research, Education and Extension Service under project number SC-1000642; and the USDA SCRI Grants Program number 2010-51181-21113. We thank X. P. Li., P. K. Bryson (Clemson University, Clemson, SC), and F. Wang (Huazhong Agricultural University, Wuhan, China) for technical support; and E. Schnabel for providing valuable comments on the manuscript.

\section{Literature Cited}

1. Avenot, H. F., and Michailides, T. J. 2007. Resistance to pyraclostrobin, boscalid, and Pristine (pyraclostrobin + boscalid) in Alternaria alternata isolates from California pistachio. (Abstr.) Phytopathology 97:S5.

2. Avenot, H. F., and Michailides T. J. 2010. Progress in understanding molecular mechanisms and evolution of resistance to succinate dehydrogenase inhibiting (SDHI) fungicides in phytopathogenic fungi 
Crop Prot. 29:643-651.

3. Avenot, H. F., Sellam, A., Karaoglanidis, G. S., and Michailides, T. J. 2008. Characterization of mutations in the iron-sulphur subunit of succinate dehydrogenase correlating with boscalid resistance in Alternaria alternata from California pistachio. Phytopathology 98:736-742.

4. Avenot, H. F., Thomas, A., Gitaitis, R. D., Langston, D. B., Jr., and Stevenson, K. L. 2011. Molecular characterization of boscalid-and penthiopyradresistant isolates of Didymella bryoniae and assessment of their sensitivity to fluopyram. Pest Manage. Sci. Online publication. doi:10.1002/ps. 2311.

5. Banno, S., Yamashita, K., Fukumori, F., Okada, K., Uekusa, H., Takagaki, M., Kimura, M., and Fujimura, M. 2009. Characterization of QoI resistance in Botrytis cinerea and identification of two types of mitochondrial cytochrome $b$ gene. Plant Pathol. 58:120-129.

6. Bardas, G. A., Veloukas, T., Koutita, O., and Karaoglanidis, G. S. 2010. Multiple resistance of Botrytis cinerea from kiwifruit to SDHIs, QoIs and fungicides of other chemical groups. Pest Manage. Sci. 66:967-973.

7. Baroffio, C. A., Siegfried, W., and Hilber, U. W. 2003. Long-term monitoring for resistance of Botrytis cinerea to anilinopyrimidine, phenylpyrrole, and hydroxyanilide fungicide in Switzerland. Plant Dis. 87:662-666.

8. Becker, W. F., von Jagow, G., Anke, T., and Steglich, W. 1981. Oudemansin, strobilurin A, strobilurin B and myxothiazol: new inhibitors of the cytochrome $b c_{1}$ segment of the respiratory chain with an E- $\beta$-methoxyacrylate system as a common structural element. FEBS Lett. 132:329-333.

9. Broomfield, P. L., and Hargreaves, J. A. 1992. A single aa change in the iron-sulphur protein subunit of succinate dehydrogenase confers resistance to carboxin in Ustilago maydis. Curr. Genet. 22:117-121.

10. Chi, M. H., Park, S. Y., and Lee, Y. H. 2009. A quick and safe method for fungal DNA extraction. Plant Pathol. J. 25:108-111.

11. De Miccolis Angelini, R. M., Habib, W., Rotolo, C., Pollastro, S., and Faretra, F. 2010. Selection, characterization and genetic analysis of laboratory mutants of Botryotinia fuckeliana (Botrytis cinerea) resistant to the fungicide boscalid. Eur. J. Plant Pathol. 128:185-199.

12. Fernández-Ortuño, D., Torés, J. A., de Vicente, A., and Pérez-García, A. 2008. Field resistance to QoI fungicides in Podosphaera fusca is not supported by typical mutations in the mitochondrial cytochrome $b$ gene. Pest Manage. Sci. 64:694-702.

13. Fernández-Ortuño, D., Torés, J. A., de Vicente, A., and Pérez-García, A. 2008. Mechanisms of resistance to QoI fungicides in phytopathogenic fungi. Int. Microbiol. 11:1-9.

14. Gisi, U., Sierotzki, H., Cook, A., and McCaffery, A. 2002. Mechanisms influencing the evolution of resistance to Qo inhibitor fungicides. Pest Manage. Sci. 58:859-867.

15. Grasso, V., Sierotzki, H., Garibaldi, A., and Gisi, U. 2006. Characterization of the cytochrome $b$ gene fragment of Puccinia species responsible for the binding site of QoI fungicides. Pest. Biochem. Physiol. 84:72-82.

16. Gullino, M., and Garibaldi, A. 1987. Control of Botrytis cinerea resistant to benzimidazoles and dicarboximides with mixtures of different fungicides. Meded. Fac. Landbouwwet. Rijksuniv. Gent 52:895-900.

17. Hagerhall, C. 1997. Succinate: quinone oxidoreductases. Variations on a conserved theme. Biochim. Biophys. Acta 1320:107-141.

18. Honda, Y., Matsuyama, T., Irie, T., Watanabe, T., and Kuwahara, M. 2000. Carboxin resistance transformation of the homobasidiomycete fungus Pleurotus ostreatus. Curr. Genet. 37:209-212.

19. Horsefield, R., Yankovskaya, V., Sexton, G., Whittingham, W., Shiomi, K., Omura, S., Byrne, B., Cecchini, G., and Iwata, S. 2006. Structural and computational analysis of the quinone-binding site of complex II (succinateubiquinone oxidoreductase) a mechanism of electron transfer and proton conduction during ubiquinone reduction. J. Biol. Chem. 281:7309-7316.

20. Ishii, H. 2008. Fungicide development in Japan. An overview. Pages 11-18 in: Modern Fungicides and Antifungal Compounds. V. H. W. Dehne, H. B. Deising, U. Gisi, K. H. Kuck, P. E. Russell, and H. Lyr, eds. 15th International Reinhardsbrunn Symposium, Friedrichroda, Germany.

21. Ishii, H., Fountaine, J., Chung, W. H., Kansako, M., Nishimura, K., Takahashi, K., and Oshima, M. 2009. Characterization of QoI-resistant field isolates of Botrytis cinerea from citrus and strawberry. Pest Manage. Sci. 65:916-922.

22. Jarvis, W. R. 1977. Botryotinia and Botrytis Species: Taxonomy, Physiology and Pathogenicity. A Guide to the Literature. Monograph number 15.

23. Jiang, J., Ding, L., Michailides, T. J., Li, H., and Ma, Z. 2009. Molecular characterization of field azoxystrobin-resistant isolates of Botrytis cinerea. Pest Biochem. Physiol. 93:72-76.

24. Keon, J. P. R., White, G. A., and Hargreaves, J. A. 1991. Isolation, characterization and sequence of a gene conferring resistance to the systemic fungicide carboxin from the maize smut pathogen Ustilago maydis. Curr. Genet. 19:475-481

25. Kim, Y. K., and Xiao, C. L. 2010. Resistance to pyraclostrobin and boscalid in populations of Botrytis cinerea from stored apples in Washington State. Plant Dis. 94:604-612.

26. Leroux, P., Fritz, R., Debieu, D., Albertini, C., Lanen, C., Bach, J., Gredt, M., and Chapeland, F. 2002. Mechanisms of resistance to fungicides in field strains of Botrytis cinerea. Pest. Manage. Sci. 58:876-888.

27. Leroux, P., Gredt, M., Leroch, M., and Walker, A. -S. 2010. Exploring mechanisms of resistance to respiratory inhibitors in field strains of Botrytis cinerea, the causal agent of gray mold. Appl. Environ. Microbiol. 76:66156630.

28. Luo, C. X., Hu, M. J., Jin, X., Yin, L. F., Bryson, P. K., and Schnabel, G. 2010. An intron in the cytochrome $b$ gene of Monilinia fructicola mitigates the risk of resistance development to QoI fungicides. Pest Manage. Sci. 66:1308-1315.

29. Markoglou, A. N., Malandrakis, A. A., Vitoratos, A. G., and Ziogas, B. N. 2006. Characterization of laboratory mutants of Botrytis cinerea resistant to QoI fungicides. Eur. Plant Pathol. 115:149-162.

30. Miyamoto, T., Ishii, H., Seko, T., Tomita, Y., Kobori, S., and Ogawara, T. 2008. Occurrence of boscalid-resistant isolates of cucumber Corynespora leaf spot fungus (C. cassiicola). Jpn. J. Phytopathol. 74:37.

31. Mondal, S. N., Bhatia, A., Shilts, T., and Timmer, L. W. 2005. Baseline sensitivities of fungal pathogens of fruit and foliage of citrus to azoxystrobin, pyraclostrobin, and fenbuconazole. Plant Dis. 89:1186-1194.

32. Oyedotun, K. S., and Lemire, B. D. 2004. The quaternary structure of the Saccharomyces cerevisiae succinate dehydrogenase-homology modeling, cofactor docking and molecular dynamics simulation studies. J. Biol. Chem. 279:9424-9431.

33. Pavan, W., Fraisse, C. W., and Peres, N. A. 2009. A web-based decision support tool for timing fungicide applications in strawberry. Agric. Biol. Eng. Dep. Fla. Coop. Ext. Serv. Univ. Fla. Se. AE450.

34. Rahman, M., Driver, J., and Louws, F. J. 2009. Evaluation of fungicides to control anthracnose fruit rot on strawberry cultivar Chandler, 2008. Plant Dis. Manage. Rep. 3:SMF019.

35. Shima, Y., Ito, Y., Kaneko, S., Hatabayashi, H., Watanabe, Y., Adachi, Y., and Yabe, K. 2009. Identification of three mutant loci conferring carboxinresistance and development of a novel transformation system in Aspergillus oryzae. Fungal Genet. Biol. 46:67-76.

36. Sierotzki, H., Frey, R., Wullschleger, J., Palermo, S., Karlin, S., Godwin, J., and Gisi, U. 2006. Cytochrome $b$ gene sequence and structure of Pyrenophora teres and $P$. tritici-repentis and implications for QoI resistance. Pest Manage. Sci. 63:225-233.

37. Skinner, W., Bailey, A., Renwick, A., Keon, J., Gurr, S., and Hargreaves, J. 1998. A single amino-acid substitution in the iron-sulphur protein subunit of succinate dehydrogenase determines resistance to carboxin in $\mathrm{Myco}$ sphaerella graminicola. Curr. Genet. 34:393-398.

38. Stammler, G., Brix, H. D., Nave, B., Gold, R., and Schoefl, U. 2008. Studies on the biological performance of boscalid and its mode of action. Pages 45-51 in: Modern Fungicides and Antifungal Compounds V. H. W. Dehne, H. B. Deising, U. Gisi, K. H. Kuck, P. E. Russell, and H. Lyr, eds. 15th International Reinhardsbrunn Symposium, Friedrichroda, Germany

39. Stammler, G., and Speakman, J. 2006. Microtiter method to test the sensitivity of Botrytis cinerea to boscalid. J. Phytopathol. 154:508-510.

40. Stevenson, K. L., Langston, D. B., and Sanders, F. 2008. Baseline sensitivity and evidence of resistance to boscalid in Didymella bryoniae. (Abstr.) Phytopathology 98:S151.

41. Stevenson, K. L., Langston, D. B., Jr., and Seebold, K. W. 2004. Resistance to azoxystrobin in the gummy stem blight pathogen documented in Georgia. Plant Health Prog. Online publication. doi:10.1094/ PHP-2004- 1207-01 RS.

42. Weber, R. W. S., and Hahn, M. 2011. A rapid and simple method for determining fungicide resistance in Botrytis. J. Plant Dis. Prot. 118:17-25.

43. Wood, P. M., and Hollomon, D. W. 2003. A critical evaluation of the role of alternative oxidase in the performance of strobilurin and related fungicides acting at the Qo site of complex III. Pest Manage. Sci. 59:499-511.

44. Yankovskaya, V., Horsefield, R., Tornroth, S., Luna-Chavez, C., Miyoshi, H., Leger, C., Byrne, B., Cecchini, G., and Iwata, S. 2003. Architecture of succinate dehydrogenase and reactive oxygen species generation. Science 299:700-704

45. Yin, Y. N., Kim, Y. K., and Xiao, C. L. 2011.Molecular characterization of boscalid resistance in field isolates of Botrytis cinerea from apple. Phytopathology 101:986-995.

46. Zhang, C., Liu, Y., Ding, L., and Zhu, G. 2011.Shift of sensitivity of Botrytis cinerea to azoxystrobin in greenhouse vegetables before and after exposure to the fungicide. Phytoparasitica 39:293-302.

47. Ziogas, B. N., and Kalamarakis, A. E. 2001. Phenylpyrrole fungicides: Mitotic instability in Aspergillus nidulans and resistance in Botrytis cinerea. J. Phytopathol. 149:301-308. 